\title{
Antimicrobial Therapy in Childhood Asthma and Wheezing
}

\author{
Arne Simon ${ }^{1}$ and Oliver Schildgen ${ }^{2}$
}

1 Children's Hospital, Medical Centre, University of Bonn, Bonn, Germany

2 Department of Virology, Institute for Medical Microbiology, Immunology, and Parasitology, Medical Centre, University of Bonn, Bonn, Germany

\section{Contents}

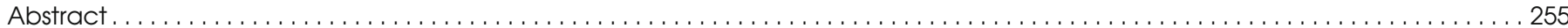

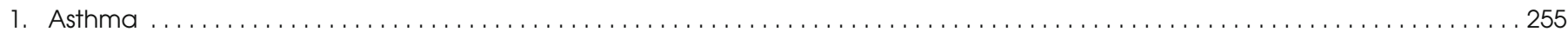

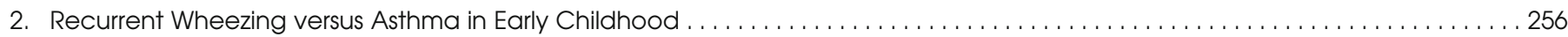

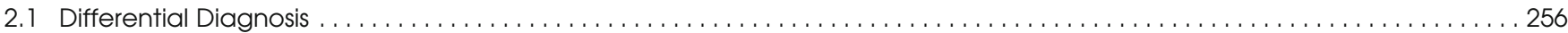

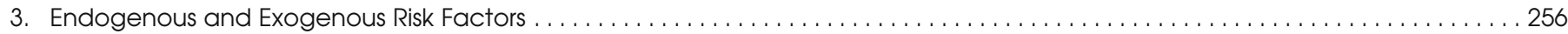

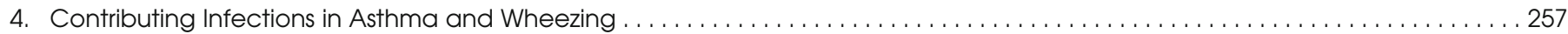

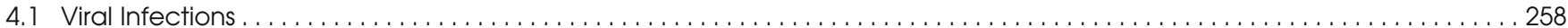

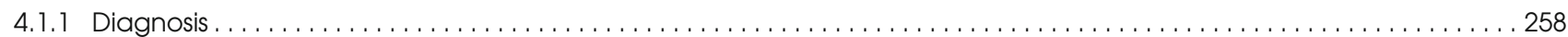

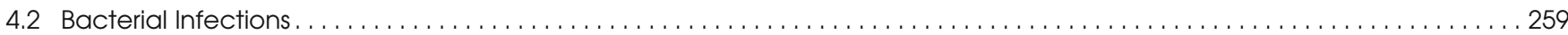

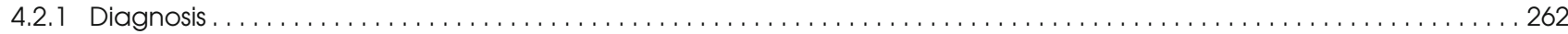

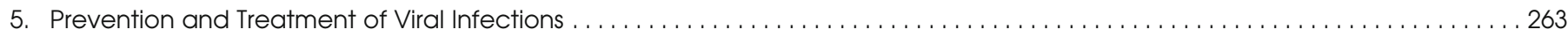

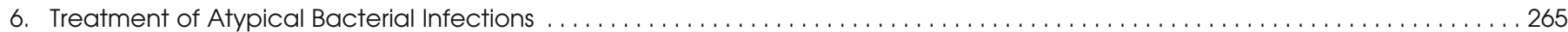

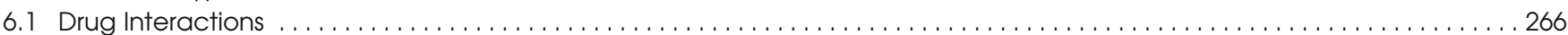

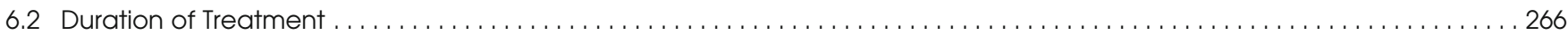

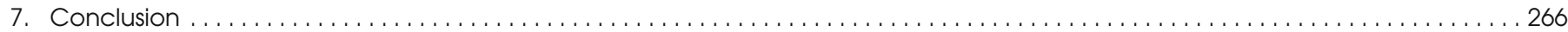

\begin{abstract}
There is an increasing number of viral and bacterial pathogens suspected of contributing to asthma pathogenesis in childhood, making it more difficult for the practitioner to make specific therapy decisions. This review discusses the role of viruses, e.g. respiratory syncytial virus, human metapneumovirus, influenza viruses and rhinoviruses, as well as the role of the atypical bacteria Chlamydophila pneumoniae and Mycoplasma pneumoniae, as contributors to childhood asthma. Diagnosis, prevention, and therapy are discussed, including a summary of drugs, i.e. macrolide antibacterials, antivirals, and vaccine regimens already available, or at least in clinical trials. For the practitioner dealing with patients every day, drug regimens are assigned to the individual pathogens and an algorithm for the management of atypical infections in patients with asthma or recurrent wheezing is presented.
\end{abstract}

Besides hereditary and atopic predispositions, viral and atypical bacterial infection of the respiratory tract may contribute to the prevalence of asthmatic symptoms, either as a simple trigger for acute exacerbations or as a significant contributor to the pathogenesis of airway inflammation and hyperresponsiveness. This article focuses on these factors in childhood asthma and wheezing, and comments on diagnostic issues and available treatment options.

\section{Asthma}

Asthma has traditionally been defined on clinical grounds as a respiratory disease characterized by recurrent and reversible airway obstruction with wheezing, cough, and dyspnea. In recent years, our understanding of asthma has expanded, and the special impact of airway inflammation and, in severe cases, of airway remodeling on pathogenesis has led to a new definition which 
describes asthma as a chronic inflammatory process in which a number of cells and cellular events are involved ${ }^{[1,2]}$ (reviewed by Yang ${ }^{[3]}$ ).

Repeated measurements of $\mathrm{FEV}_{1}$ (a general index of airway resistance) and PEF (which measures large airway resistance, which accounts for $80 \%$ of total resistance) have gained a global consensus to guide therapeutic interventions in patients $>5$ years of age. Bronchial hyperreactivity is defined as a $20 \%$ decrease in $\mathrm{FEV}_{1}$ at $\leq 8 \mathrm{mg} / \mathrm{mL}$ methacholine challenge or $>15 \%$ increase in $\mathrm{FEV}_{1}$ after the administration of albuterol (salbutamol) in patients with baseline airflow obstruction $\left(\mathrm{FEV}_{1}<70 \%\right)$ in whom a methacholine challenge cannot be performed.

Patients with asthma also exhibit elevated levels of fractionated exhaled nitric oxide, which can be utilized as a marker of airway inflammation. The measurement of fractionated exhaled nitric oxide has been shown to enhance the diagnosis of asthma, detect deterioration in the control of asthma, and monitor response to anti-inflammatory therapy, as levels decrease after inhaled corticosteroid treatment, ${ }^{[4]}$ especially in individuals with asthma and atopy. ${ }^{[5]}$ The measurement of fractionated exhaled nitric oxide may become an important tool in clinical practice. ${ }^{[6]}$ Furthermore, an increase in the sputum-associated immune cell (in particular eosinophil) count should be taken into account during diagnosis, since it is believed to reflect underlying airway inflammation. ${ }^{[7-9]}$ The eosinophil count can also be used to predict asthma control after the discontinuation of inhaled corticosteroids. ${ }^{[9]}$

\section{Recurrent Wheezing versus Asthma in Early Childhood}

The risk of subsequent asthma in an infant with a first episode of wheezing is difficult to predict, as nearly $90 \%$ of those events are triggered by viral infections, ${ }^{[10,11]}$ in particular respiratory syncytial virus (RSV), human metapneumovirus (HMPV), parainfluenza virus (PIV), influenza virus (IV), rhinovirus, and adenovirus (ADV). HMPV and RSV in particular, but also rhinoviruses ${ }^{[12]}$ may contribute to acute exacerbations of asthma, and infection may represent the initial event in a history of asthma.

However, considering the plethora of viral agents the infant's immature immune system is confronted with after the shield of maternally derived antibodies has waned, recurrent wheezing may just be the consequence of recurrent infections or (in the cases of RSV and HMPV) even reinfections. In contrast to younger children, the majority of children aged $\geq 3$ years who are hospitalized for acute wheezing show characteristics of atopy in their medical history. ${ }^{[3,10,11,13,14]}$

It is important, therefore, to emphasize that recurrent wheezing rarely results in the final diagnosis of asthma in children $\leq 3$ years, as they may represent transient early wheezers. Although transient early wheezers were found to have normal-to-subnormal lung function at age 7 years, children with asthmatic symptoms already show significant impairment of expiratory flow volumes. ${ }^{[15]}$ Any uncertainty, however, in the diagnosis of asthma in younger children must not result in undertreatment with anti-inflammatory (controller) drugs, in addition to short-acting $\beta_{2}$-adrenoceptor agonists (reliever drugs). ${ }^{[3,16]}$

\subsection{Differential Diagnosis}

Particularly in infants and young children, some important differential diagnoses have to be excluded before recurrent wheezing is attributed to bronchial hyperreactivity and asthma. In children who did not receive the full set of vaccinations in their first year of life, whooping cough should always be excluded and droplet precautions should be implemented as long as the results of Bordetella pertussis diagnostics are pending.

An aspirated foreign body may cause recurrent episodes of pulmonary infection. This makes it reasonable not only to confirm the clinical diagnosis of pneumonia with chest x-ray in hospitalized children, but also to control for the complete resolution of pulmonary infiltrates after 4-6 weeks. Cystic fibrosis should also be excluded (sweat test) in any child with severe recurrent respiratory tract infection.

The medical history of the patient may reveal prematurity and prolonged ventilator (supplemental oxygen) therapy with subsequent bronchopulmonary dysplasia. Gastroesophageal reflux disease (nocturnal attacks of wheezing and cough) may trigger recurrent wheezing and respiratory infections due to microaspirations. Sinusitis as a cause of posterior drainage-associated chronic cough should be considered in school age children with asthma symptoms. ${ }^{[17]}$ Chronic persistent infection of the airways with atypical bacteria such as Mycoplasma spp. or Chlamydophila spp. may cause recurrent wheezing episodes; ${ }^{[18-20]}$ beyond simple acute exacerbation, some recent lines of evidence suggest that infection with these atypical bacteria may play an additional role in the pathogenesis of asthma. ${ }^{[21]}$

\section{Endogenous and Exogenous Risk Factors}

As a result of continuous research, the number of potential risk factors (e.g. tobacco smoke, house dust mite, mould, pet or cockroach allergens, and genetic background of atopy) for the development of asthma is increasing (reviewed by Arruda et al.). ${ }^{[22]}$

Breastfeeding or, alternatively, the use of a documented hypoallergenic formula for at least 4-6 months seems to be protective. ${ }^{[23]}$ This effect may be explained by the observation that maternal intake of the probiotic Lactobacillus rhamnosus GG 
Table I. Overview of viral and bacterial pathogens that are considered contributory to childhood asthma and treatment options

\begin{tabular}{|c|c|c|c|c|}
\hline Pathogen & Description & Diagnostic procedure & Therapy options & Comment \\
\hline \multicolumn{5}{|l|}{ Viruses } \\
\hline RSV & $\begin{array}{l}\text { Paramyxovirus (RNA } \\
\text { genome) }\end{array}$ & $\begin{array}{l}\text { RT-PCR, culture, ELISA, } \\
\text { IF }\end{array}$ & Ribavirin, palivizumab & $\begin{array}{l}\text { Only in severely } \\
\text { immunocompromised childrena }\end{array}$ \\
\hline HMPV & $\begin{array}{l}\text { Paramyxovirus (RNA } \\
\text { genome) }\end{array}$ & RT-PCR, culture, IF & None & \\
\hline Influenza (A/B) & $\begin{array}{l}\text { Orthomyxovirus (segmented } \\
\text { RNA genome) }\end{array}$ & $\begin{array}{l}\text { RT-PCR, culture, ELISA, } \\
\text { IF }\end{array}$ & Oseltamivir, zanamivir & $\begin{array}{l}\text { Oseltamivir should be } \\
\text { administered in children with } \\
\text { asthma and confirmed } \\
\text { influenza }\end{array}$ \\
\hline PIV & $\begin{array}{l}\text { Paramyxovirus (RNA } \\
\text { genome) }\end{array}$ & RT-PCR, culture, ELISA & Ribavirin & $\begin{array}{l}\text { Only in severely } \\
\text { immunocompromised children }\end{array}$ \\
\hline Adenoviruses & $\begin{array}{l}\text { Linear double-strand DNA } \\
\text { genome }\end{array}$ & PCR, culture, ELISA & Cidofovir, ribavirin, vidarabine ${ }^{b}$ & $\begin{array}{l}\text { Only in severely } \\
\text { immunocompromised children }\end{array}$ \\
\hline $\begin{array}{l}\text { Coronaviruses (SARS, } \\
\text { hCoV-NL63) }\end{array}$ & RNA genome & RT-PCR & None & \\
\hline Rhinoviruses & Picornavirus (RNA genome) & RT-PCR, culture, ELISA & Pleconaril, rupintrivirc & $\begin{array}{l}\text { Only in severely } \\
\text { immunocompromised children }\end{array}$ \\
\hline hBoV & $\begin{array}{l}\text { Parvovirus (linear single- } \\
\text { strand DNA genome) }\end{array}$ & PCR & None & \\
\hline \multicolumn{5}{|l|}{ Bacteria } \\
\hline $\begin{array}{l}\text { Chlamydophila } \\
\text { pneumoniae }\end{array}$ & & $\begin{array}{l}\text { PCR, MIF, serology (IgM, } \\
\operatorname{lgG})\end{array}$ & \multicolumn{2}{|c|}{$\begin{array}{l}\text { Prolonged course of clarithromycin or azithromycin (first-line) or } \\
\text { doxycycline (children }>8 \text { years of age) }\end{array}$} \\
\hline Mycoplasma pneumoniae & & PCR, serology (IgM, IgG) & \multicolumn{2}{|c|}{$\begin{array}{l}\text { Prolonged course of clarithromycin or azithromycin (first-line) or } \\
\text { doxycycline (children }>8 \text { years of age) }\end{array}$} \\
\hline
\end{tabular}

a Patients undergoing an allogenic blood stem cell or bone marrow transplantation. Premature infants on mechanical ventilation with severe bronchopulmonary dysplasia or hemodynamically unstable congenital heart disease (only anecdotal evidence from small case series for both indications in premature infants).

b In small series and clinical trials.

c In clinical trials (unlicensed).

ELISA = enzyme-linked immunosorbent assay; hBoV = human bocavirus; hCoV-NL63 = human coronavirus NL63; HMPV = human metapneumovirus; IF = immunofluorescence; Ig = immunoglobulin; MIF = microimmunofluorescence; $\mathbf{P C R}=$ polymerase chain reaction; $\mathbf{P I V}=$ parainfluenza virus; $\mathbf{R S V}=$ respiratory syncytial virus; $\mathbf{R T}-\mathbf{P C R}=$ reverse transcriptase polymerase chain reaction; SARS = severe acute respiratory syndrome.

during late pregnancy followed by administration of L. rhamnosus GG to the infant for the first 6 months of life significantly decreased the proportion of children with atopic eczema in the verum group. ${ }^{[24]}$ Thus, gut microflora might be a hitherto unexplored source of natural immunomodulators and probiotics for prevention of atopic disease. ${ }^{[24,25]}$ However, any protective effect of frequent early exposure to (potential) pathogens and infections on the prevalence of asthma has been questioned in further studies. ${ }^{[26,27]}$ Thereby, only one prospective trial ${ }^{[28]}$ fosters the hypothesis that antibacterial treatment in infancy is related to a higher risk of asthma later in life. ${ }^{[29,30]}$

Nevertheless, too many wheezing episodes in infants triggered by viral infection are treated with antibacterials, although the risk of bacterial superinfection is in general $<5 \%$ (influenza exclud- ed). ${ }^{[31-33]}$ This misuse of antibacterials may have biased studies that evaluated antibacterial treatment in early infancy as a risk factor for subsequent asthma. ${ }^{[29]}$ However, it should be noted that in contrast to this misuse, the sophisticated use of antibacterials, in particular macrolides, may downregulate prolonged inflammation, increase mucus clearance, prevent biofilm formation, and also decrease the bacterial virulence (reviewed by Shinkai and Rubin). ${ }^{[34]}$

\section{Contributing Infections in Asthma and Wheezing}

Table I summarizes pathogens that are suspected to exacerbate or contribute to the development of childhood asthma. 


\subsection{Viral Infections}

For a long time it was believed that respiratory viruses were solely responsible for the 'common cold' and for serious airway disease only in high risk patients such as prematurely born infants, the elderly, and the immunocompromised. Subsequently, it was widely recognized that viral respiratory infections may cause severe lower respiratory tract disease in immunocompetent individuals. ${ }^{[35]}$ In addition, viral respiratory tract infections are closely linked to wheezing in infancy and to hospitalization for acute wheezing before 3 years of age. ${ }^{[10,11,36,37]}$ By comparison, a large majority of wheezing children aged 3-18 years display additional atopic characteristics that may be critical as a risk factor for hospitalization and an adverse response to viral infections, especially to rhinovirus, the most prevalent causative agent in this age group. ${ }^{[37]}$ In asthmatic children, bronchial hyperresponsiveness after a single 'natural cold' has been found to last 5-11 weeks. ${ }^{[38]}$ Beyond RSV and rhinovirus, the newly detected viruses HMPV, human coronavirus NL63 (hCoV-NL63), and human bocavirus may substantially contribute to acute asthma exacerbations. ${ }^{[39-44]}$ The more severe clinical course of viral bronchiolitis in infants has been linked to inherited abnormalities of pulmonary function ${ }^{[45]}$ and to certain risk factors like chronic lung disease of prematurity, hemodynamically relevant congenital heart disease, neurologic impairment, and immunodeficiency. ${ }^{[46]}$

In addition to acute aggravation of any pre-existing airway disease, RSV infection of the lower respiratory tract, in infants, severe enough to cause hospitalization has been linked to subsequent bronchial hyperreactivity, recurrent wheezing and asthma in school age children up to the age of 13 years. ${ }^{[13,14,47,48]}$ Interestingly, children with recurrent wheezing after their first RSV bronchiolitis displayed elevated IgE antibodies against common respiratory and food allergens as well. ${ }^{[13,47]}$ Thus, it has been speculated that lower respiratory tract infection with RSV triggers a general shift of the immune system in favor of atopy (dominance of $\mathrm{T}$ helper type 2 response, upregulating IgE production with higher levels of interleukin (IL)-4, IL5, IL10 and IL8 in bronchial secretions). ${ }^{[45,49-52]}$ Similar changes in the immune system have been implicated for the devastating consequences of the first RSV immunization campaign with a formalin-inactivated RSV vaccine that resulted in severe and even lethal illness in the immunized children. ${ }^{[53]}$

In a series of recent publications on a retrospective study from the Kuopio University Hospital, Finland, rhinoviruses were detected in 27 (33\%) of 81 respiratory samples from children who had been hospitalized for wheezing in infancy. ${ }^{[54]}$ As single viral findings, rhinoviruses were associated with the development of asthma 7 years later $(\mathrm{p}=0.047$; odds ratio [OR], $4.14 ; 95 \% \mathrm{CI}$
1.02, 16.77 vs rhinovirus-negative cases [by logistic regression adjusted for age, sex, and atopic dermatitis on entry]). Korrpi et al. ${ }^{[5]}$ reported on the same patients and compared children with RSV with those with rhinovirus infection. Oxygen saturation values were lower in children with RSV infection. There were no significant differences in respiratory rates or scores combining wheezing and retractions. The children with rhinovirus infection were older (median 13 vs 5 months) and presented more often with atopic dermatitis (OR, 16.7; 95\% CI 2.22, 100) and blood eosinophilia (OR, 2.22; 95\% CI 1.04, 50). The groups did not differ from each other with regard to total serum IgE. The risk of subsequent asthma was increased about 5-fold after RSV-induced wheezing, and $\geq 10$-fold after rhinovirus-induced wheezing in the most recent patient collective. ${ }^{[56]}$

Lemanske et al. investigated the role of RSV infection in a prospectively followed (from birth to 3 years of age) cohort of 285 children at genetically high risk for developing allergic respiratory diseases. ${ }^{[12]}$ When viral etiology was considered, first-year wheezing illnesses caused by rhinovirus infection were the strongest predictor of subsequent third-year wheezing (OR, 6.6; $\mathrm{p}<0.0001)$. Moreover, $63 \%$ of the infants who wheezed during rhinovirus seasons continued to wheeze in the third year of life, compared with only $20 \%$ of all other infants (OR, 6.6; p < 0.0001). Also, similar mechanisms have been speculated to be active in severe bronchiolitis caused by rhinovirus, ${ }^{[57]}$ but the evidence that rhinovirus-like RSV contributes to the pathogenesis of asthma in childhood is not as consistent and requires investigation in further prospective trials.

Juntti et al. ${ }^{[58]}$ showed that children hospitalized for RSV infection in infancy still differed in interferon (IFN)- $\gamma$ and soluble intercellular adhesion molecule-1 (sICAM-1) [CD54] production 6-10 years after the infection. Data from 51 children admitted to hospital for RSV infection during the first year of life suggested that the pathogenesis of asthma and wheezing after an early RSV infection may be different from that in children without an early RSV infection. The latent or chronic inflammatory state of the airways in asthmatic or atopic individuals may alleviate the infection with rhinovirus due to an increased expression of sICAM-1, hitherto known as the key receptor only for rhinoviruses and necessary for their adhesion to the respiratory epithelium. ${ }^{[59]}$

\subsubsection{Diagnosis}

The diagnostics of viral respiratory tract infections relies on different methods and, in general, depends on the skills and experiences of a virological laboratory.

Fortunately, some of the viruses causing respiratory infections can be cultivated in permissive cell cultures, provided that the necessary equipment and technology are available. However, as 
the culture method is sometimes time-consuming and the viruses may be extremely difficult to recover, e.g. in the case of hCoVNL63 and HMPV, ${ }^{[42-44,60]}$ other more rapid diagnostic methods like reverse transcriptase polymerase chain reaction (RT-PCR) or antigen detection assays are preferred in clinical practice. Antigen detection by the enzyme-linked immunosorbent assay (ELISA) method is available for RSV, IV, PIV and ADV and provides a positive or negative result between 15 minutes and 3-6 hours. However, until such assays are developed for routine use for newly detected pathogens like HMPV or hCoV NL-63, ${ }^{[43]}$ the method of choice is to detect the viral nucleic acid. Thus, PCR or RT-PCR plays a crucial role in the detection of newly detected viral respiratory pathogens. For most of these agents, however, it is still unknown how long the PCR remains positive in respiratory specimens after the cessation of the clinical illness.

Besides the high sensitivity of the RT-PCR/PCR, this method is advantageous in detecting additional infection by another virus, commonly described as co-infection. However, as the viral RNA may take 5-6 weeks to disappear from nasal mucus, e.g. after the onset of symptomatic respiratory infection by rhinoviruses, ${ }^{[61]}$ it may not be clear which of the viruses detected is responsible for the clinical symptoms. Therefore, the duration of detection should be investigated, to avoid false positive PCR results, weeks or possibly months after the first infection.

\subsection{Bacterial Infections}

Any chronic respiratory tract infection may contribute to the aggravation of symptoms in patients with asthma, as the immunological response to the infection may foster the development of bronchial hyperreactivity, the inception of new atopic symptoms against common respiratory allergens, and the chronic inflammatory and remodeling process of the airways, ${ }^{[50,51]}$ although the contribution to the latter remains highly speculative. On the other hand, chronic pulmonary inflammation and its deleterious effects on mucociliary clearance, drainage of mucus and cell debris and reduced airway patency enable the development of viral and bacterial superinfections.

There is a consensus that typical bacterial respiratory pathogens such as Streptococcus pneumoniae or Haemophilus influenzae have not been associated with the exacerbation or the inception of childhood asthma, and that the routine administration of $\beta$-lactams to patients with asthma exacerbations provides no significant benefit. ${ }^{[52,62]}$

The potential contribution of atypical bacteria, in particular Mycoplasma pneumoniae and Chlamydophila pneumoniae, to the onset and persistence of childhood asthma is still a matter of ongoing debate. ${ }^{[52]}$ Due to the extraordinary high incidence of viral respiratory infections in infants, the contribution of atypical bacterial pathogens to the inception of asthmatic symptoms in this age group might be underestimated. ${ }^{[52,63]}$ A recently published review by Johnston and Martin ${ }^{[64]}$ on this issue included nine studies in pediatric patients (table II), as well as other studies in adults. The main results of these trials in children are included in table II. Johnston and Martin came to the conclusion that in 15 out of 19 studies, a relationship was evident between asthma and infections with $M$. pneumoniae and C. pneumoniae. ${ }^{[64]}$

C. pneumoniae is a respiratory pathogen distributed worldwide, which causes conjunctivitis, pharyngitis, bronchitis and pneumonia (with pleural effusion in some cases). A subacute onset and a prolonged period of convalescence with ongoing malaise and cough are characteristic. While symptoms of acute sinusitis often accompany acute infection with $C$. pneumoniae, its causative role in chronic sinusitis in school age children has been questioned. ${ }^{[74]}$ Nearly $10 \%$ of community-acquired pneumonias in children $\geq 5$ years of age are caused by C. pneumoniae; the highest incidence is found in school-age children and adolescents, and about $50 \%$ of adults display serum IgG antibodies against the pathogen. It is an obligate intracellular parasitic bacterium which utilizes the energy metabolism of the human host cells for its replication. $C$. pneumoniae is transmitted by direct contact, droplets and (to a much lesser extent) by aerosol nuclei or fomites in conditions of high relative humidity. The incubation period is approximately 21 days, ${ }^{[52,75]}$ and the attack rates are relatively low, even in family contacts. Infection with $C$. pneumoniae is usually followed by a specific immune response of $\operatorname{IgM}, \operatorname{IgG}$ and $\operatorname{IgA}$ antibodies against certain bacterial antigens. This humoral immune response is not obligate; in particular, infants and young children may fail to mount sufficient antibodies in spite of culture-confirmed infection. ${ }^{[75-80]}$ Thus, it is not clear whether the immune response can be used to differentiate between colonization and infection in young children.

Hahn et al. first observed in $1991^{[81]}$ that 9 of 19 wheezing adults displayed serologic signs of an infection with $C$. pneumoniae. These findings were extended 5 years later when the same group suggested that the detection of $\operatorname{IgA}$ antibodies against C. pneumoniae corresponded with a higher probability of recent asthma symptoms. ${ }^{\left[{ }^{[2]}\right.}$ Furthermore, in school-age children with wheezing, Cunningham et al. ${ }^{[67]}$ observed an unusually high number of individuals with low-grade $C$. pneumoniae infection.

In contrast to viral respiratory infections, $C$. pneumoniae contributes only rarely to acute asthma exacerbations, ${ }^{[69]}$ but an association between chronic infection with $C$. pneumoniae and the subsequent onset of asthma has been suggested by some authors. Nagy et al. ${ }^{[70]}$ found a significantly higher risk of asthma in children infected with $C$. pneumoniae isolates with variant man- 
Table II. A summary of studies investigating the contribution of the atypical bacteria Mycoplasma pneumoniae and Chlamydophila pneumoniae to childhood asthma ${ }^{[64]}$

\begin{tabular}{lll}
\hline Study (year) & Inclusion & Diagnostic methods \\
\hline Emre et al. ${ }^{[65]}$ (1994) & 118 children with acute wheezing & Culture; serology, including \\
& (emergency department); 41 healthy & IgG, IgM (MIF) and IgE (EIA)
\end{tabular}
(emergency department); 41 healthy matched controls

Emre et al. ${ }^{[66]}(1995)$

Culture-positive children with stable asthma $(n=14) ; 11$ culture-negative asthmatic children; 11 culture-negative controls

Longitudinal study over 13 months in 96 children (aged 9-11y) with asthma NPA routinely collected at defined intervals and in case of any clinical exacerbation (no controls)

Mills et al. ${ }^{[68]}(2000)$

198 subjects from a prospective birth cohort study at age 11y $(n=66)$ and at age 21y $(\mathrm{n}=96)$

Esposito et al. ${ }^{[69]}(2000)$

71 children aged $2-14 y$ with acute wheezing; 80 healthy matched controls. Clarithromycin administered at the discretion of the attending physician (15 mg/kg/day for 10 days)
Culture

Serology, including IgG, IgM (MIF) and IgE (EIA)

PCR (NPA); EIA for secretory $\lg A$

Serology, including IgG and $\lg \mathrm{A}(\mathrm{MIF})$

PCR (NPA); serology using MIF for $C$, pneumoniae and EIA for M. pneumoniae (acute and convalescent after $\geq 4$ weeks); skin prick test for common allergens to demonstrate atopy

Results and comment

C. pneumoniae in $11 \%$ (wheezers) vs $4.9 \%$ (controls)

$7(58.3 \%)$ of 12 children with positive cultures had no detectable antibody and only $3(25 \%)$ children had serologic evidence of acute infection

$9(75 \%)$ of the infected patients experienced an improvement of their reactive airway disease after treatment with erythromycin or clarithromycin (culture switched to negative in 100\%)

IgE against $C$. pneumoniae was detected significantly more often in culture-positive asthmatic children than in culture-negative asthmatic children and in controls ( $86 \%$ vs $18 \%$ vs $22 \%$; $p<$ 0.001 and $p<0.006$, respectively)

The authors speculated that the production of specific lgE against $C$. pneumoniae may foster the development of asthma 43 of $96(45 \%)$ children with asthma displayed a positive $C$. pneumoniae PCR at least at one time point of the study C. pneumoniae-specific secretory lgA antibodies were $>7$ times greater in subjects who reported $\geq 4$ exacerbations in the study ( $p$ $<0.02)$

M. pneumoniae was only detected in 4 of 357 samples (possibly related to the sensitivity of the PCR protocol)

No statistically significant correlation between symptoms suggestive of asthma in the previous 12 months and either IgG or IgA antibody levels. Individuals with high IgG titers $(\geq 128)$ even showed a protective effect against ever having asthma (OR 0.29 ; $\mathrm{Cl} 0.10,0.87$ )

Conclusion: C. pneumoniae is not a major risk factor

M. pneumoniae in $22.5 \%(10 \%<4$ years; $38.7 \% \geq 5$ years); in children with wheezing $\geq 5$ years, significantly more often detected than in healthy controls $(8.7 \% ; p=0.0003)$. Significantly more children with $M$. pneumoniae showed recurrent wheezing (93.7\% vs $29.1 \%$ in pts without $M$. pneumoniae infection; $p<$ $0.001)$

C. pneumoniae in $15.5 \%$ ( $10 \%<4$ years; $22.6 \% \geq 5$ years); in children with wheezing $\geq 5$ years, significantly more often detected than in healthy controls $(0 \% ; p=0.001)$. Significantly more children with $C$. pneumoniae showed recurrent wheezing $(72.7 \%$ vs $38.3 \%$ in pts without $C$. pneumoniae infection; $p=$ $0.04)$

None of the pts infected and treated with clarithromycin $(n=11)$ but $69.2 \%$ of the pts infected but untreated $(n=13)$ showed a new episode of wheezing $(p=0.0005)$ in the following 3 months No significant difference in the prevalence of atopy between wheezing children with and without infection 
Esposito et al. ${ }^{[19]}$ (2002) 25 children (aged 2-14y) with an acute episode of wheezing (15 with acute $M$. pneumoniae infection); 16 healthy matched controls (8 with laboratory evidence of asymptomatic acute $M$. pneumoniae infection)

Nagy et al. ${ }^{[70]}(2003)$

139 children with asthma; 174 healthy control subjects

82 symptomatic children (aged $2-16 y$ ) with $\geq 3$ episodes of recurrent reversible wheezing; 27 asymptomatic asthmatic outpatients as controls

(2003)

Korppi et al. ${ }^{[72]}(2004)$

122 children aged 1-6y, treated for new asthma as inpatients or outpatients; 244 controls, matched by age, sex and municipality

Biscardi et al. ${ }^{[18]}(2004)$

119 children (2-15y) with previously diagnosed asthma, hospitalized with exacerbation; 51 children with first asthma attack followed-up at 12 months; 152 children with stable asthma or allergic rhinitis as contro group

Webley et al. ${ }^{[73]}(2005)$

Blood and BAL samples from 70 pediatric patients undergoing flexible fiberoptic bronchoscopy (including 42 pts with asthma and 38 pts with various respiratory disorders); 70 matched control subjects without respiratory illness for M. pneumoniae

Serology (ELISA); MBL variant alleles of the isolated $C$. pneumoniae strains (PCR)

In symptomatic children, IL-5 concentrations were significantly higher in those with acute $M$. pneumoniae infection $(p<0.0001)$. Children with acute $M$. pneumoniae infection and wheeze had higher IL-5 concentrations ( $p<0.0001$ )

IL- 5 has been shown to be essential for the development of airway hyperresponsiveness in RSV infection[21]

Higher risk of asthma development in infected children with variant $M B L$ alleles than infected children with normal MBL genotype. Especially high asthma risk in children with chronic or recurrent infection (positive results for both $\lg A$ and $\lg G$; adjusted OR, 5.38; Cl 1.75, 14.36; $p=0.01$ )

IF for influenza, RSV, PIV, ADV, and CV; PCR for rhinovirus and enterovirus; serology for $M$. pneumoniae and C. pneumoniae

MIF for $C$. pneumoniae and $C$. trachomatis antibodies; EIA for C. pneumoniae antibodies

PCR (NPA); serology (acute and convalescent after $\geq 4$ weeks

PCR (BAL and blood); culture; electrochemiluminescence assay for $\lg \mathrm{E}$ cultured on macrophages. Forty percent of the PCR-positive and
Viral pathogens were diagnosed in $38 \%$ of symptomatic patients. Serology revealed a low prevalence of $M$. pneumoniae and $C$. pneumoniae infection in symptomatic patents of $5 \%$ each. Although atypical infections were linked to prolonged asthmatic symptoms, no correlation between infection and severity of chronic asthma or asthma exacerbations was found

IgG antibodies to $C$. pneumoniae, though common in 1- to 6 -year-old children as detected by EIA (31-36\%), did not differ between newly diagnosed asthma patients and controls The prevalence of IgA antibodies (EIA) was much lower (4-7\%) but likewise not different between patients and controls

M. pneumoniae in $24(20 \%)$; C. pneumoniae in $4(3.4 \%)$ Subgroup with first asthma attack $(\mathrm{n}=51)$ : M. pneumoniae in $50 \%(p<0.01)$; C. pneumoniae in $8.3 \%$

Control group: $M$. pneumoniae IgM in $5.2 \%(p<0.005)$

Risk of recurrent wheezing was higher in first-attack children with M. pneumoniae or C. pneumoniae infection ( $62 \%$ vs $27 \%$; $p<$ 0.05 ). Conclusion: $M$. pneumoniae may play a role in the onset of asthma (50\%) and increases the risk of recurrence

$44 \%$ of the BAL samples were PCR-positive for Chlamydophila, and $31 \%$ of the PCR-positive samples were positive when $20 \%$ of the culture-positive samples, respectively, were from patients with asthma

$34.3 \%$ of the blood samples were positive for Chlamydophila compared with $11 \%$ of 70 matched nonrespiratory controls ( $p<$ $0.01) ; 24 \%$ of the positive blood cultures from the respiratory group were from patients with asthma

Elevation of total IgE was strongly associated with BAL culture positivity for Chlamydophila ( 77.3 vs $18.8 \%$; $<<0.0001)$

ADV = adenovirus; $\mathbf{B A L}=$ bronchoalveolar lavage $\mathbf{C I}=95 \%$ confidence interval; $\mathbf{C V}=$ coronavirus; EIA = enzyme immunoassay; $\mathbf{E L I S A}=$ enzyme-linked immunosorbent assay IF = immunofluorescence; Ig = immunoglobulin; IL = interleukin; $\mathbf{M B L}=$ mannose-binding lectin; $\mathbf{M I F}=$ microimmunofluorescence; $\mathbf{N P A}=$ nasopharyngeal aspirate; OR = odds ratio; $\mathbf{P C R}=$ polymerase chain reaction; $\mathbf{P I V}=$ parainfluenza virus; $\mathbf{p t s}=$ patients; $\mathbf{R S V}=$ respiratory syncytial virus 
nose-binding lectin alleles (confirmed by PCR), in particular in those with chronic infection (confirmed by both positive IgG and IgA antibodies). Mills et al., ${ }^{[68]}$ however, could not determine a significant correlation between $C$. pneumoniae serology and asthma (table II). Because of its retrospective nature (antibodies were detected in stored serum samples), no results from culture or PCR were available to identify which patients harbored $C$. pneumoniae in their airways. In addition, only $22.9 \%$ of all individuals reporting asthma symptoms showed a bronchial hyperreactivity and the authors did not differentiate according to the two age groups (11 and 21 years; table II). The authors emphasized in their discussion that seroconversion is not universally associated with clinical infection and questioned the principle of assessing the effect of a respiratory infection on a chronic pulmonary disease simply by the measurement of antibody titers in serum.

On the contrary, two groups found an inverse correlation between $C$. pneumoniae respiratory tract infection and the inception of asthma or allergic rhinitis in children. ${ }^{[83,84]}$ Such data about the role of $C$. pneumoniae in the inception and development of asthma in children are intriguing, but somewhat controversial; further well designed studies are needed. One recently published study ${ }^{[73]}$ (table II) not only detected $C$. pneumoniae in bronchoalveolar lavage (BAL) samples from asthmatic children with PCR, but also confirmed the viability of the pathogen in culture, and correlated an elevated total level of $\operatorname{IgE}$ with lavage culture positivity for $C$. pneumoniae. The authors concluded that viable C. pneumoniae are frequently present in BAL specimens from symptomatic children with asthma. ${ }^{[73]}$

M. pneumoniae is a common pathogen in upper and lower airway infections including otitis media, pharyngitis, ${ }^{[85]}$ tracheobronchitis and pneumonia in all age groups older than 12 months. ${ }^{[86]}$ M. pneumoniae is an extracellular mucosal pathogen attached to the respiratory epithelium via a specific part of its cell, the organelle. The extent to which it invades and replicates intracellularly in vivo is not known. ${ }^{[21]}$ The cellular and humoral immune response to the infection is responsible for clinical illness and airway injury. Acute infection is accompanied by lymphocyte proliferation and the release of tumor necrosis factor (TNF)- $\alpha$, IFN $\gamma$, and various interleukins (IL2, IL4, IL5, IL6, IL8, IL10, and IL18). ${ }^{[21]}$

However, the distinct role of M. pneumoniae in asthma pathogenesis still has to be resolved. ${ }^{[16,50]}$ Biscardi and colleagues ${ }^{[18]}$ have reported the highest prevalence of M. pneumoniae infection; $50 \%$ of children with a first asthma attack, and $20 \%$ of children with previously diagnosed asthma and acute severe exacerbation. Although the authors searched for viruses, they did not use PCR methods and no immunofluorescence assay was available for the detection of rhinovirus, the most important viral pathogen in asthma exacerbations in school-aged children. ${ }^{[22,37,55,63]}$

\subsubsection{Diagnosis}

A series of very detailed investigations of the clinical, laboratory, and radiologic presentations of community-acquired pneumonia in children under the age of 5 years revealed that no combination of clinical signs, host acute phase response markers at any cutoff value, or radiologic findings reliably differentiates between bacterial and viral or between atypical and typical pneumonia in this age group. ${ }^{[72,87-89]}$ Thus, microbiologic diagnostic efforts are indispensable to identify the responsible respiratory pathogen.

Initially, $C$. pneumoniae was designated as TWAR strain of $C$. psittaci, ${ }^{[90]}$ but differences in DNA sequences, epidemiology, and also pathogenicity led to the actual classification of this pathogen. Furthermore, there is a high prevalence of $\mathrm{IgG}$ antibodies against C. pneumoniae in the general population ( $>50 \%$ in adults). ${ }^{[00]}$ Thus, the laboratory diagnosis, in general, is based on serologic testing.

As a result of a consensus conference held at the Centers for Disease Control and Prevention, USA, Dowell and colleagues ${ }^{[1]}$ concluded that acute infection with $C$. pneumoniae is accompanied by the appearance of $\operatorname{IgM}$ antibodies that can be detected 2-3 weeks after the onset of clinical symptoms. Thereafter, IgM antibodies are detectable up to 2-6 months and are replaced by low titers of IgG antibodies that firstly appear $6-8$ weeks after infection. Dowell and colleagues concluded that the use of a single parameter will not lead to a complete diagnosis and that PCR, although not yet standardized, will be of increasing importance as a future tool for diagnosis. Furthermore, they stated that 'there are no wholly satisfactory serological methods for diagnosis of $C$. pneumoniae infection. ${ }^{[91]}$

The PCR method for pathogen detection is of increasing importance for the second atypical bacterial pathogen related to asthma, M. pneumoniae. However, the major obstacle to the use of PCR as the single method for the detection of $M$. pneumoniae or $C$. pneumoniae is that it does not distinguish between viable and nonviable bacteria, for example after antibacterial chemotherapy. ${ }^{[92]}$ Thus, at least one other method is recommended for the laboratory diagnosis of both infections.

The most frequently used method to detect specific antibodies in the majority of studies that investigated an association between asthma and $C$. pneumoniae infection is the microimmunofluorescence test. ${ }^{[64,91]}$ Alternative serological assays have been described, but the lack of commercial availability and limited specificity (cross-reactive antibodies) have impeded their broader use in practice. ${ }^{[91,92]}$ 
The laboratory diagnosis of $M$. pneumoniae is more complex and even more difficult. Although M. pneumoniae can be cultivated on solid media, its growth is extremely slow ( $\geq 6$ days), and the culturing methods are extremely insensitive. Thus, it is difficult to get a rapid diagnostic result with this method. However, $M$. pneumoniae can be isolated from swabs, retronasal aspirates, sputum, or BAL. In all cases where the subsequent culturing of the pathogen is required or desired, the specimen should be solved (i.e. material should be mixed with medium) in adequate transportation media. For rapid detection, the material can be investigated with enzyme immunoassays, oligonucleotide hybridization methods, or PCR assays.

While culturing on solid-phase media, middle-sized granulated colonies without the typical 'fried egg' appearance are formed. For orientation, M. pneumoniae can be identified via glucose cleavage reactions, hemadsorption, and hemolysis, and finally the identification procedure can be finished by a growth inhibition test and/or epifluorescence. Because of the insensitive culturing method and the difficulties of other methods, in addition to the direct or indirect detection of M. pneumoniae, serologic testing can and should be performed. Traditionally, such serologic detection of a M. pneumoniae infection was performed by complement fixation. This assay has the general limitations that it is: (i) impossible to differentiate antibody subclasses; (ii) lacks specificity; and thus, (iii) cannot differentiate between acute, chronic, or previous infections. ${ }^{[64]}$ Meanwhile, the commonly used serologic test that replaced complement fixation is the ELISA method, which has the major advantage that there some assays commercially available and these tests specifically differentiate between different stages of the infection. ${ }^{[64]}$

All in all, the diagnosis of atypical respiratory tract infection is still laborious, sophisticated, expensive, and time consuming. There is an urgent need for sensitive, specific, standardized, and economically inexpensive diagnostic tests that can be used at the bedside or at least yield results within $2-6$ hours. ${ }^{[18]}$ Only if the pathogen can be easily identified and its detection can be definitely attributed to infection (vs colonization) will it be possible to confirm its role in the inception of the chronic inflammatory process; prospective randomized studies on the best therapeutic intervention can then be performed. ${ }^{[69]}$ Modern multiplex PCR approaches detect an extended spectrum of pathogens in parallel, thereby reducing costs for material and personnel. Although this approach is intriguing, the 'reality check' of some published methods often yields much lower detection rates than expected. This problem will probably be overcome by the recent 'upgrade' of these multiplex assays as described by Khanna et al. ${ }^{[93]}$ These authors developed the Pneumoplex ${ }^{\circledR 1}$ assays that combine multiplex PCR and hybridization assays while being highly specific and highly sensitive.

\section{Prevention and Treatment of Viral Infections}

Almost 50 years after the first description of RSV, physicians attending children with viral respiratory tract disease and asthma are still awaiting the development of effective and economically inexpensive medications for the prevention and treatment of respiratory viral infections in infants. ${ }^{[45]}$ For the majority of respiratory viruses there is no specific therapy available to impede infection or to inhibit viral replication in the infected host. In most cases, treatment is symptomatic with no specific intervention fighting the pathogen. In contrast to bronchiolitis in hospitalized infants and children without a history of asthma or recurrent wheezing, ${ }^{[31,94]}$ the early administration of systemic corticosteroids represents the primary means of treatment in severe asthma exacerbations, ${ }^{[3,16]}$ irrespective of any acute infection (the only exception is a varicella zoster virus infection in which systemic corticosteroids should only be given under systemic aciclovir coverage).

The neuraminidase inhibitors oseltamivir and zanamivir are active against influenza viruses and are available for the treatment of microbiologically confirmed influenza. ${ }^{[95]}$ These substances inhibit the enzymatic activity of neuraminidase and are thought to prevent the release of newly budded progeny virions from the cell surface. The neuraminidase inhibitors have to be used very early (within the first 72 hours) during the course of the disease, or even as a chemoprophylaxis. Thus, a rapid laboratory diagnostic test that detects the viral RNA or the viral antigen is mandatory to guide decisions on treatment.

Another possibility to prevent influenza-triggered asthma is to prevent the infection by vaccination. Although this possibility is highly desirable, the major disadvantage is that vaccination targets actual influenza strains. In epidemic seasons, when new strains emerge (as most recently observed for the avian influenza virus H5N1), a new specific vaccine must be developed and, in general, is available only in the middle of the ongoing epidemic or for the next epidemic season. However, we strongly recommend vaccination of any high-risk group, especially those with an increased risk of asthma. In the near future, newer vaccine formulations and live, attenuated influenza vaccine strains ${ }^{[96-99]}$ may complement current vaccination strategies.

A specific passive immunoprophylaxis and also a nonspecific antiviral therapy are available to prevent or treat infections with human RSV. The first option is immunoprophylaxis with

1 The use of trade names is for product identification purposes only and does not imply endorsement. 
palivizumab, a humanized monoclonal antibody binding to the highly conserved F protein of both RSV-A and RSV-B subtypes. ${ }^{[32]}$ The efficacy of palivizumab (mainly a significant reduction of the percentage of children who have to be rehospitalized with RSV infection in the first 24 months of life) was tested in two well-designed, prospectively randomized, double-blind multicenter studies. ${ }^{[100]}$ However, the prophylactic use of this antibody is limited due to its high cost; thus, its application is recommended only for high-risk premature infants, for infants with hemodynamically relevant congenital heart disease, ${ }^{[46]}$ and (not at the same level of evidence) in RSV-infected patients after allogenic blood stem cell transplantation. ${ }^{[101,102]}$

- Antiviral therapy for RSV infections is possible and sometimes successful with ribavirin, administered by the inhalation of aerosols from a small-particle aerosol generator. This therapy may be an option in the case of life-threatening RSV infections in mechanically ventilated premature infants or in severely immunocompromised children. In the latter group, ribavirin has been suggested as a treatment option in patients with severe influenza or parainfluenza virus infection. ${ }^{[102]}$ Even in those high-risk populations, its routine use is controversial due to a lack of evidence of a significant benefit in randomized controlled studies, as well as cost issues, and potential toxicity (and teratogenicity) in both patients and exposed caregivers. ${ }^{[103]}$ One study of ribavirin use in infants with severe bronchiolitis, observed a long-term benefit on subsequent airway hyperreagibility. ${ }^{[104]}$ Even if this could be confirmed in further controlled trials, no valid clinical or laboratory parameter indicates which subgroup of patients will experience such a positive outcome.

- As reviewed by Weinberger, ${ }^{[52]}$ a number of compounds are known to display only marginal cytotoxic effects while being highly active against RSV in inoculated tissue culture. Three compounds are already being tested in phase I or phase II trials: pleconaril, RSV 604 (A 60444), and RF I641. ${ }^{[52,105]}$ However, neither ribavirin nor any of the new therapeutic agents active against RSV have been assessed or licensed for use in children with recurrent wheezing or asthma. ${ }^{[52]}$

The respiratory viruses most frequently detected in school-age children with asthma are the rhinoviruses. While no specific treatment against rhinoviruses is available yet, an increasing number of promising drug candidates are under development or even in the early phase of clinical trials. One of these drugs that has successfully passed a phase II clinical trial is rupintrivir, ${ }^{[106]}$ a selective irreversible inhibitor of the rhinoviral 3C-protease which is administered intranasally. It is a peptidomimetic compound with poor aqueous solubility and low oral bioavailability in animals, ${ }^{[107]}$ but it was well tolerated in healthy adult volunteers. ${ }^{[108]}$ Pleconaril may be another future option for the treatment of rhinovirus infections as it inhibits the attachment of virus to host cell receptors and the uncoating of viral nucleic acid. ${ }^{[109]}$ Pleconaril can be applied orally and is distributed to the upper and lower airways after enteral absorption. Infection with rhinoviruses, however, has not been a major inclusion criterion in clinical studies of pleconaril. $^{[110]}$

ICAM-1 is an important cellular receptor for the attachment of rhinoviruses. There have been experimental approaches to inhibit the virus-receptor interaction by monoclonal antibodies or antagonistic molecules. One antibody-like compound CFY 196 is a recombinant antibody fusion protein and may be a promising candidate for further investigations and clinical trials. Another compound, sICAM-1 (tremacamra), consists of an ICAM-1 derivate in which the transmembrane and intracellular domains have been truncated.

Specific therapies or vaccinations are lacking for human metapneumovirus and respiratory coronaviruses. Furthermore, data on experimental usage of antivirals in vitro that should inhibit the replication of these viruses are ambivalent and not very promising, and even the development of specific vaccines has not yet been as successful as expected.

For human metapneumovirus, as for the other 'untreatable' viral pathogens, prospective controlled studies are needed to confirm or refute the efficacy of any therapeutic intervention in infants and children with recurrent wheezing, asthma, bronchiolitis, or pneumonia. It should be proven in prospectively randomized double-blind studies with sufficient power that a certain therapeutic intervention has a positive impact on illness severity (breath rate and oxygen saturation), length of inpatient care, and the necessity to admit the patient to the intensive care unit or to start mechanical ventilation. It is also important to identify evidencebased treatment methods to avoid the unjustified consumption of financial resources. In this context, systemic treatment with corticosteroids ${ }^{[31,111,112]}$ or inhalation treatment with beta mimetics or adrenaline (epinephrine) ${ }^{[31,111,112]}$ should be investigated critically. For example, in epidemiologic studies published up till 2005, 26-44\% of all HMPV-infected hospitalized pediatric patients received systemic corticosteroids, and half of them were treated with bronchodilators. Due to the increasing number of clinically relevant viral respiratory pathogens and also the increasing number of newly developed antiviral drugs, the absolute prerequisite for a specific treatment remains a rapid and specific diagnostic approach.

Specific therapy options for viral infections are summarized in table I. 


\section{Treatment of Atypical Bacterial Infections}

Taken together, results from Italy ${ }^{[69,113]}$ and France ${ }^{[18]}$ support the use of antimicrobials in patients with asthma and microbiologically confirmed $M$. pneumoniae or $C$. pneumoniae infection. Schmidt et al. ${ }^{[14]}$ recently demonstrated that in children with therapy-refractory bronchitis or pneumonia, bronchial $C$. pneumoniae co-infection was associated with more severe disease. In their study, and others, ${ }^{[87,115]}$ adequate antibacterial therapy for C. pneumoniae infection was shown to improve pulmonary function. Figure 1 presents an algorithm for the management of atypical pulmonary infections in patients with asthma or recurrent wheezing.

In this context, the principle aims of treatment are:

- The infection should be eradicated, not only suppressed. ${ }^{[79,80,116]}$ However, this seems to be not so easy to achieve in $C$. pneumoniae infections. Therefore, some authors recommend an empirical second cycle of treatment if symptoms persist or recur. ${ }^{[90]}$

- Relief of acute symptoms in patients with acute infection should be prompt (those infections are self-limiting diseases in immunocompetent persons).

- The number and the severity of recurrent wheezing exacerbations during follow up should be reduced. ${ }^{[18,69]}$

- The inflammatory stimulus of chronic pulmonary infection with atypical pathogens on the underlying pulmonary disease should be stopped and the adverse effects of the cellular and humoral immune response on bronchial hyperreactivity should be contained. ${ }^{[19,21,113]}$

The microbiologic targets are obligate intracellular organisms (C. pneumoniae) or bacteria without a common Gram-positive/ Gram-negative cell wall, rendering both pathogens a priori resistant to all $\beta$-lactams, glycopeptides, and carbapenems. In addition, M. pneumoniae is not susceptible to sulfonamides, rifampicin, or linezolid.

First-line agents for the treatment of infections due to $M$. pneumoniae or $C$. pneumoniae in children are the macrolides (erythromycin, clarithromycin, or roxithromycin) and the azalide azithromycin. Erythromycin and clarithromycin are available as intravenous preparations if the condition of the child does not allow oral medication. In children $\geq 8$ years of age, intravenous doxycycline may be used as a feasible alternative, although there are no comparative studies on the use of doxycycline in children and adolescents besides its use in the treatment of tick-borne infections, melioidosis, or brucellosis. ${ }^{[117-120]}$ However, at least in the US, azithromycin is available for intravenous use, but not clarithromycin, demonstrating that not only scientific reasons, but
Any child with severe asthma exacerbation (hospitalization), recurrent wheezing ${ }^{\text {a }}$ (at least one emergency outpatient visit) or first asthma attack with radiology-confirmed pneumonia

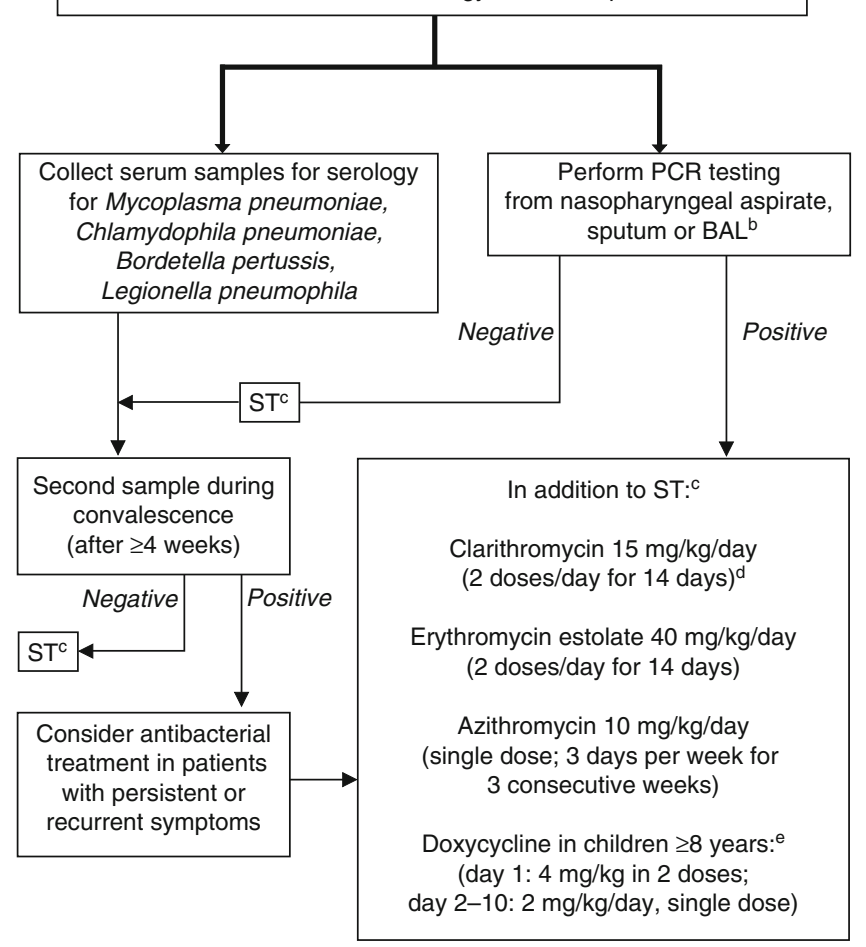

Fig. 1. Algorithm for the management of atypical infections in patients with asthma or recurrent wheezing. BAL = bronchoalveolar lavage; $\mathbf{P C R}=$ polymerase chain reaction; $\mathbf{S T}=$ standard therapy. $\mathbf{a} \geq 3$ episodes of reversible obstructive airway disease irrespective of any viral infection. $\mathbf{b}$ In intubated, mechanically ventilated patients. c Controller medication to be adjusted to the clinical severity of the symptoms (systemic/inhaled corticosteroids or montelukast). ${ }^{[3,16]}$ To avoid an unnecessary increase in selective pressure and an increase in macrolide-resistant pathogens, community-acquired pneumonia in outpatients should be treated with amoxicillin/ clavulanic acid or sulbactam/ampicillin or cefuroxime as first-line agents unless there are distinct features of atypical pneumonia in the medical history (i.e. a combination of subacute onset, low-grade fever, hoarseness, dry 'hacking' cough, malaise, myalgia, or headache). $\mathbf{d}$ Consider the use of systemic corticosteroids and intravenous immunoglobulins in any patient with extrapulmonary manifestations of $M$. pneumoniae disease (CNS, arthritis, nephropathy, or carditis). Fluoroquinolones (ciprofloxacin, levofloxacin, or moxifloxacin) and the ketolid telithromycin are third-line agents for the treatment of atypical pneumonia in pediatric patients with underlying immunodeficiency or life-threatening infections. e Do not use doxycycline against $B$. pertussis or $L$. pneumophila infection.

also individual local legal restrictions, may limit the use of an antimicrobial agent.

Third-line agents for the treatment of atypical pneumonia in severely immunocompromised children and adolescents are the fluoroquinolones (i.e. levofloxacin and moxifloxacin) or the ketolide telithromycin. Due to potential toxicities, ${ }^{[121]}$ licensing issues and general considerations not to increase selective pressure on resistant pathogens, ${ }^{[122]}$ the use of these agents is not standard in 
children with recurrent wheezing or asthma, and are thus beyond the scope of this review.

From a microbiologic perspective, it seems reasonable to use clarithromycin ( $15 \mathrm{mg} / \mathrm{kg} /$ day in two doses for at least 14 days) as a first-line agent as it displays very promising in vitro sensitivity results, with minimum inhibitory concentrations $\leq 0.001-0.125$ $\mu \mathrm{g} / \mathrm{mL}$ (as do erythromycin and azithromycin). A prospective randomized study of 124 children treated with clarithromycin (tested against erythromycin ethylsuccinate $40 \mathrm{mg} / \mathrm{kg}$ /day in two or three divided doses in 110 patients) confirmed clinical and radiologic success in $98 \%$, and an eradication of M. pneumoniae in $100 \%(\mathrm{n}=9) .{ }^{[123]}$ C. pneumoniae was eradicated in $79 \%$ (culture). The gastrointestinal tolerability of clarithromycin seems to be better than that of erythromycin and it can be administered twice daily.

In contrast to azithromycin, the pharmacokinetic pattern of clarithromycin does not result in prolonged subtherapeutic plasma levels and an increased risk of subsequent colonization with macrolide-resistant pneumococci. ${ }^{[124-126]}$ This clinically relevant observation has been refuted by others. ${ }^{[28]}$ Arguments for the use of azithromycin are: it is highly active in vitro; ${ }^{[21]}$ at least two randomized controlled trials in children confirmed its efficacy and safety against atypical community-acquired pneumonia; ; $^{[27,128]}$ children find the color and taste of the oral suspension of azithromycin agreeable; and the drug is well tolerated. ${ }^{[129]}$ It is administered in a single daily dose. In addition, a substantial line of evidence suggests that azithromycin displays favorable immunomodulatory and anti-inflammatory effects in patients with chronic inflammatory pulmonary diseases like cystic fibrosis, ${ }^{[130,131]}$ and bronchiolitis obliterans after stem cell transplantation. ${ }^{[132,133]}$ Interestingly, Esposito et al. ${ }^{[113]}$ investigated the use of azithromycin in children $>8$ years of age and with a physician's diagnosis of recurrent respiratory infections. Their results in the group of patients without an atypical bacterial infection demonstrated a significant benefit, which might have been related to the anti-inflammatory properties of azithromycin.

\subsection{Drug Interactions}

Treatment with erythromycin and, to a lesser, but still considerable extent, clarithromycin may result in clinically relevant, potentially toxic interactions with drugs that are (as the two macrolides) metabolized via hepatic cytochrome P450 microsomal enzymes. ${ }^{[129]}$ Most relevant in patients with asthma is the profound elevation of theophylline plasma levels and the enhanced cardiotoxicity of antihistamines like terfenadine (prolonged QT interval, increased risk of ventricular arrhythmias, and torsade des pointes). Azithromycin does not interact with these enzymes and may be combined without subsequent problems, e.g. for example with cyclosporin after stem cell or organ transplantation. ${ }^{[134]}$

\subsection{Duration of Treatment}

No controlled trials are available on the optimal duration of treatment in childhood atypical bacterial tracheobronchitis or pneumonia. Considering the observation of persistent colonization after conventional treatment regimens, in particular in $C$. pneumoniae infections, ${ }^{[79,80,116]}$ it seems reasonable to use a prolonged treatment schedule in children with asthma and confirmed atypical bacteria infection, as suggested by Esposito et al. ${ }^{[113]}$ for azithromycin (i.e. $10 \mathrm{mg} / \mathrm{kg} / \mathrm{day}$ for 3 days per week in 3 consecutive weeks). Alternatively, the use of clarithromycin for at least 14-21 days may be considered ${ }^{[90]}$ Further well designed, randomized and controlled trials are clearly needed to examine the effectiveness of different antibiotics against $M$. pneumoniae or $C$. pneumoniae and the optimal dose and duration of therapy in various patient populations. ${ }^{[135]}$

\section{Conclusion}

Although the number of pathogens suspected to be associated with acute or chronic asthma pathogenesis in childhood is increasing, the number of options for specific therapies available now or in the near future is also increasing. Thus, before starting a therapy it is strongly recommended that clinicians perform a rapid clinical and laboratory diagnosis accompanied by a detailed history. Thereafter, a specific and individual therapy regimen should be considered in order to avoid the development of resistance and to minimize drug-specific adverse effects or unnecessary drug interactions. In this manner, treatment may avoid acute and/or chronic asthma in the affected patient.

\section{Acknowledgments}

The authors are supported by grants from the Else Kröner-FreseniusStiftung (Grant Number A 01/05//F 00) and the Herbert-Reeck-Stiftung, and have no conflict of interest directly relevant to the content of this review. The authors thank Carola Maiworm for critical comments on the manuscript.

\section{References}

1. GINA, Global Initiative for Asthma. Pocket guide for asthma management and prevention [online]. Available from URL: http://www.ginasthma.org [Accessed 2005 Oct]

2. NAEPP, National Asthma Education and Prevention Program. Expert panel report 2: guidelines for the diagnosis and management of asthma. NIH Publication No. 97-4051. Bethesda (MD): National Heart, Lung and Blood Institute, NIH, US Department of Health and Human Services, 1997: 1-147

3. Yang KD. Asthma management issues in infancy and childhood. Treat Respir Med 2005; 4 (1): 9-20

4. Spallarossa D, Battistini E, Silvestri M, et al. Time-dependent changes in orally exhaled nitric oxide and pulmonary functions induced by inhaled corticosteroids in childhood asthma. J Asthma 2001; 38 (7): 545-53 
5. Zeidler M, Corren J. Hydrofluoroalkane formulations of inhaled corticosteroids for the treatment of asthma. Treat Respir Med 2004; 3 (1): 35-44

6. Zitt M. Clinical applications of exhaled nitric oxide for the diagnosis and management of asthma: a consensus report. Clin Ther 2005; 27 (8): 1238-50

7. Bousquet J, Chanez P, Lacoste JY, et al. Eosinophilic inflammation in asthma. N Engl J Med 1990; 323 (15): 1033-9

8. Jatakanon A, Lim S, Kharitonov SA, et al. Correlation between exhaled nitric oxide, sputum eosinophils, and methacholine responsiveness in patients with mild asthma. Thorax 1998; 53 (2): 91-5

9. Deykin A, Lazarus SC, Fahy JV, et al. Sputum eosinophil counts predict asthma control after discontinuation of inhaled corticosteroids. J Allergy Clin Immunol 2005; 115 (4): 720-7

10. Heymann PW, Carper HT, Murphy DD, et al. Viral infections in relation to age, atopy, and season of admission among children hospitalized for wheezing. $\mathrm{J}$ Allergy Clin Immunol 2004; 114 (2): 239-47

11. Williams JV, Tollefson SJ, Heymann PW, et al. Human metapneumovirus infection in children hospitalized for wheezing. J Allergy Clin Immunol 2005; 115 (6): 1311-2

12. Lemanske Jr RF, Jackson DJ, Gangnon RE, et al. Rhinovirus illnesses during infancy predict subsequent childhood wheezing. J Allergy Clin Immunol 2005; 116 (3): 571-7

13. Schauer U, Hoffjan S, Bittscheidt J, et al. RSV bronchiolitis and risk of wheeze and allergic sensitisation in the first year of life. Eur Respir J 2002; 20 (5): 1277-83

14. Sigurs N, Gustafsson PM, Bjarnason R, et al. Severe respiratory syncytial virus bronchiolitis in infancy and asthma and allergy at age 13. Am J Respir Crit Care Med 2005; 171 (2): 137-41

15. Lau S, Illi S, Sommerfeld C, et al. Transient early wheeze is not associated with impaired lung function in 7-yr-old children. Eur Respir J 2003; 21 (5): 834-41

16. Lemanske Jr RF, Busse WW. 6. Asthma. J Allergy Clin Immunol 2003; 111 (2 Suppl.): S502-19

17. Tsao $\mathrm{CH}$, Chen LC, Yeh KW, et al. Concomitant chronic sinusitis treatment in children with mild asthma: the effect on bronchial hyperresponsiveness. Chest 2003; 123 (3): 757-64

18. Biscardi S, Lorrot M, Marc E, et al. Mycoplasma pneumoniae and asthma in children. Clin Infect Dis 2004; 38 (10): $1341-6$

19. Esposito S, Droghetti R, Bosis S, et al. Cytokine secretion in children with acute Mycoplasma pneumoniae infection and wheeze. Pediatr Pulmonol 2002; 34 (2): 122-7

20. Tsai MH, Huang YC, Chen CJ, et al. Chlamydial pneumonia in children requiring hospitalization: effect of mixed infection on clinical outcome. J Microbiol Immunol Infect 2005; 38 (2): 117-22

21. Waites KB, Talkington DF. Mycoplasma pneumoniae and its role as a human pathogen. Clin Microbiol Rev 2004; 17 (4): 697-728

22. Arruda LK, Sole D, Baena-Cagnani CE, et al. Risk factors for asthma and atopy. Curr Opin Allergy Clin Immunol 2005; 5 (2): 153-9

23. Halken S. Prevention of allergic disease in childhood: clinical and epidemiological aspects of primary and secondary allergy prevention. Pediatr Allergy Immunol 2004; 15 Suppl. 16: 4-32

24. Kalliomaki M, Salminen S, Poussa T, et al. Probiotics and prevention of atopic disease: 4-year follow-up of a randomised placebo-controlled trial. Lancet 2003; 361 (9372): 1869-71

25. Rinne M, Kalliomaki M, Arvilommi H, et al. Effect of probiotics and breastfeeding on the bifidobacterium and lactobacillus/enterococcus microbiota and humoral immune responses. J Pediatr 2005; 147 (2): 186-91

26. Kramer MS, Guo T, Platt RW, et al. Does previous infection protect against atopic eczema and recurrent wheeze in infancy? Clin Exp Allergy 2004; 34 (5): 753-6

27. Platts-Mills TA, Erwin E, Heymann P, et al. Is the hygiene hypothesis still a viable explanation for the increased prevalence of asthma? Allergy 2005; 60 Suppl. 79: 25-31

28. McKeever TM, Lewis SA, Smith C, et al. Mode of delivery and risk of developing allergic disease. J Allergy Clin Immunol 2002; 109 (5): 800-2

29. Celedon JC, Fuhlbrigge A, Rifas-Shiman S, et al. Antibiotic use in the first year of life and asthma in early childhood. Clin Exp Allergy 2004; 34 (7): 1011-6

30. Celedon JC, Weiss ST. Use of antibacterials in infancy: clinical implications for childhood asthma and allergies. Treat Respir Med 2004; 3 (5): 291-4

31. Fitzgerald DA, Kilham HA. Bronchiolitis: assessment and evidence-based management. Med J Aust 2004; 180 (8): 399-404
32. Ogra PL. Respiratory syncytial virus: the virus, the disease and the immune response. Paediatr Respir Rev 2004; 5 Suppl. A: S119-26

33. Randolph AG, Reder L, Englund JA. Risk of bacterial infection in previously healthy respiratory syncytial virus-infected young children admitted to the intensive care unit. Pediatr Infect Dis J 2004; 23 (11): 990-4

34. Shinkai M, Rubin BK. Macrolides and airway inflammation in children. Paediatr Respir Rev 2005; 6 (3): 227-35

35. Papadopoulos NG. Do rhinoviruses cause pneumonia in children? Paediatr Respir Rev 2004. 5 Suppl A: S191-S195

36. Jartti T, van den Hoogen B, Garofalo RP, et al. Metapneumovirus and acute wheezing in children. Lancet 2002; 360 (9343): 1393-4

37. Jartti $\mathrm{T}$, Lehtinen $\mathrm{P}$, Vuorinen $\mathrm{T}$, et al. Respiratory picornaviruses and respiratory syncytial virus as causative agents of acute expiratory wheezing in children. Emerg Infect Dis 2004; 10 (6): 1095-101

38. Xepapadaki P, Papadopoulos NG, Bossios A, et al. Duration of postviral airway hyperresponsiveness in children with asthma: effect of atopy. J Allergy Clin Immunol 2005; 116 (2): 299-304

39. Allander T, Tammi MT, Eriksson M, et al. Cloning of a human parvovirus by molecular screening of respiratory tract samples. Proc Natl Acad Sci U S A 2005; 102 (36): 12891-6

40. Schildgen O, Geikowski T, Glatzel T, et al. New variant of the human metapneumovirus (HMPV) associated with an acute and severe exacerbation of asthma bronchiale. J Clin Virol 2004; 31 (4): 283-8

41. Schildgen O, Wilkesmann A, Simon A. Wheezing in patients with human metapneumovirus infection. J Allergy Clin Immunol 2006; 117 (1): 223

42. van den Hoogen BG, de Jong JC, Groen J, et al. A newly discovered human pneumovirus isolated from young children with respiratory tract disease. Nat Med 2001; 7 (6): 719-24

43. van der Hoek L, Pyrc K, Jebbink MF, et al. Identification of a new human coronavirus. Nat Med 2004; 10 (4): 368-73

44. Williams JV, Tollefson SJ, Heymann PW, et al. Human metapneumovirus infection in children hospitalized for wheezing. J Allergy Clin Immunol 2005; 115 (6): 1311-2

45. Gern JE, Rosenthal LA, Sorkness RL, et al. Effects of viral respiratory infections on lung development and childhood asthma. J Allergy Clin Immunol 2005; 115 (4): 668-74

46. Meissner HC. Selected populations at increased risk from respiratory syncytial virus infection. Pediatr Infect Dis J 2003; 22 (2 Suppl.): S40-4

47. Sigurs N, Bjarnason R, Sigurbergsson F, et al. Asthma and immunoglobulin E antibodies after respiratory syncytial virus bronchiolitis: a prospective cohort study with matched controls. Pediatrics 1995; 95 (4): 500-5

48. Stein RT, Sherrill D, Morgan WJ, et al. Respiratory syncytial virus in early life and risk of wheeze and allergy by age 13 years. Lancet 1999; 354 (9178): 541-5

49. Contoli M, Caramori G, Mallia P, et al. Mechanisms of respiratory virus-induced asthma exacerbations. Clin Exp Allergy 2005; 35 (2): 137-45

50. Montalbano MM, Lemanske Jr RF. Infections and asthma in children. Curr Opin Pediatr 2002; 14 (3): 334-7

51. Weinberger M. Clinical patterns and natural history of asthma. J Pediatr 2003; 142 (2 Suppl.): S15-9

52. Weinberger M. Respiratory infections and asthma: current treatment strategies. Drug Discov Today 2004; 9 (19): 831-7

53. Polack FP, Karron RA. The future of respiratory syncytial virus vaccine development. Pediatr Infect Dis J 2004; 23 (1 Suppl.): S65-73

54. Kotaniemi-Syrjanen A, Vainionpaa R, Reijonen TM, et al. Rhinovirus-induced wheezing in infancy: the first sign of childhood asthma? J Allergy Clin Immunol 2003; 111 (1): 66-71

55. Korppi M, Kotaniemi-Syrjanen A, Waris M, et al. Rhinovirus-associated wheezing in infancy: comparison with respiratory syncytial virus bronchiolitis. Pediatr Infect Dis J 2004; 23 (11): 995-9

56. Hyvarinen MK, Kotaniemi-Syrjanen A, Reijonen TM, et al. Teenage asthma after severe early childhood wheezing: an 11-year prospective follow-up. Pediatr Pulmonol 2005; 40 (4): 316-23

57. Jartti T, Makela MJ, Vanto T, et al. The link between bronchiolitis and asthma. Infect Dis Clin North Am 2005; 19 (3): 667-89

58. Juntti H, Kokkonen J, Dunder T, et al. Serum concentrations of interferon-gamma and intercellular adhesion molecule-1 eight years after an early respiratory syncytial virus infection. Clin Exp Allergy 2005; 35 (1): 59-63 
59. Papi A, Papadopoulos NG, Stanciu LA, et al. Reducing agents inhibit rhinovirusinduced up-regulation of the rhinovirus receptor intercellular adhesion molecule-1 (ICAM-1) in respiratory epithelial cells. FASEB J 2002; 16 (14): 1934-6

60. Vicente D, Montes M, Cilla G, et al. Human metapneumovirus and chronic obstructive pulmonary disease. Emerg Infect Dis 2004; 10 (7): 1338-9

61. Jartti T, Lehtinen $\mathrm{P}$, Vuorinen $\mathrm{T}$, et al. Persistence of rhinovirus and enterovirus RNA after acute respiratory illness in children. J Med Virol 2004; 72 (4): 695-9

62. NAEPP. Use of antibiotics to treat asthma exacerbations. J Allergy Clin Immunol 2002; 110 (5 Suppl.): S180-3

63. Gern JE. Viral respiratory infection and the link to asthma. Pediatr Infect Dis J 2004; 23 (1 Suppl.): S78-86

64. Johnston SL, Martin RJ. Chlamydophila pneumoniae and Mycoplasma pneumoniae: a role in asthma pathogenesis? Am J Respir Crit Care Med 2005; 172 (9): 1078-89

65. Emre U, Roblin PM, Gelling M, et al. The association of Chlamydia pneumoniae infection and reactive airway disease in children. Arch Pediatr Adolesc Med 1994; 148 (7): 727-32

66. Emre U, Sokolovskaya N, Roblin PM, et al. Detection of anti-Chlamydia pneumoniae IgE in children with reactive airway disease. J Infect Dis 1995; 172 (1): $265-7$

67. Cunningham AF, Johnston SL, Julious SA, et al. Chronic Chlamydia pneumoniae infection and asthma exacerbations in children. Eur Respir J 1998; 11 (2): 345-9

68. Mills GD, Lindeman JA, Fawcett JP, et al. Chlamydia pneumoniae serological status is not associated with asthma in children or young adults. Int J Epidemiol 2000; 29 (2): 280-4

69. Esposito S, Blasi F, Arosio C, et al. Importance of acute Mycoplasma pneumoniae and Chlamydia pneumoniae infections in children with wheezing. Eur Respir J 2000; 16 (6): 1142-6

70. Nagy A, Kozma GT, Keszei M, et al. The development of asthma in children infected with Chlamydia pneumoniae is dependent on the modifying effect of mannose-binding lectin. J Allergy Clin Immunol 2003; 112 (4): 729-34

71. Thumerelle C, Deschildre A, Bouquillon C, et al. Role of viruses and atypical bacteria in exacerbations of asthma in hospitalized children: a prospective study in the Nord-Pas de Calais region (France). Pediatr Pulmonol 2003; 35 (2): 75-82

72. Korppi M, Paldanius M, Hyvarinen A, et al. Chlamydia pneumoniae and newly diagnosed asthma: a case-control study in 1 to 6-year-old children. Respirology 2004; 9 (2): 255-9

73. Webley WC, Salva PS, Andrzejewski C, et al. The bronchial lavage of pediatric patients with asthma contains infectious Chlamydia. Am J Respir Crit Care Med 2005; 171 (10): 1083-8

74. Cultrara A, Goldstein NA, Ovchinsky A, et al. The role of Chlamydia pneumoniae infection in children with chronic sinusitis. Arch Otolaryngol Head Neck Surg 2003; 129 (10): 1094-7

75. Smyth A. Pneumonia due to viral and atypical organisms and their sequelae. $\mathrm{Br}$ Med Bull 2002; 61: 247-62

76. Esposito S, Blasi F, Bellini F, et al. Mycoplasma pneumoniae and Chlamydia pneumoniae infections in children with pneumonia. Mowgli Study Group. Eur Respir J 2001; 17 (2): 241-5

77. Esposito S, Blasi F, Allegra L, et al. Use of antimicrobial agents for communityacquired lower respiratory tract infections in hospitalised children. Eur J Clin Microbiol Infect Dis 2001; 20 (9): 647-50

78. Esposito S, Principi N. Asthma in children: are chlamydia or mycoplasma involved? Paediatr Drugs 2001; 3 (3): 159-68

79. Hammerschlag MR. Advances in the management of Chlamydia pneumoniae infections. Expert Rev Anti Infect Ther 2003; 1 (3): 493-503

80. Hammerschlag MR. Chlamydia trachomatis and Chlamydia pneumoniae infections in children and adolescents. Pediatr Rev 2004; 25 (2): 43-51

81. Hahn DL, Dodge RW, Golubjatnikov R. Association of Chlamydia pneumoniae (strain TWAR) infection with wheezing, asthmatic bronchitis, and adult-onset asthma. JAMA 1991; 266 (2): 225-30

82. Hahn DL, Anttila T, Saikku P. Association of Chlamydia pneumoniae IgA antibodies with recently symptomatic asthma. Epidemiol Infect 1996; 117 (3): 513-7

83. Normann E, Gnarpe J, Gnarpe H, et al. Chlamydia pneumoniae infection predicts a reduced risk for subsequent atopic disease. Acta Paediatr 2005; 94 (6): 705-10

84. Schmidt SM, Muller CE, Wiersbitzky SK. Inverse association between Chlamydia pneumoniae respiratory tract infection and initiation of asthma or allergic rhinitis in children. Pediatr Allergy Immunol 2005; 16 (2): 137-44
85. Esposito S, Blasi F, Bosis S, et al. Aetiology of acute pharyngitis: the role of atypical bacteria. J Med Microbiol 2004; 53 (Pt 7): 645-51

86. Clyde Jr WA. Mycoplasma pneumoniae respiratory disease symposium: summation and significance. Yale J Biol Med 1983; 56 (5-6): 523-7

87. Korppi M. Mixed microbial aetiology of community-acquired pneumonia in children. APMIS 2002; 110 (7-8): 515-22

88. Korppi M, Remes S, Heiskanen-Kosma T. Serum procalcitonin concentrations in bacterial pneumonia in children: a negative result in primary healthcare settings. Pediatr Pulmonol 2003; 35 (1): 56-61

89. Korppi M. Non-specific host response markers in the differentiation between pneumococcal and viral pneumonia: what is the most accurate combination? Pediatr Int 2004; 46 (5): 545-50

90. Kuo CC, Jackson LA, Campbell LA, et al. Chlamydia pneumoniae (TWAR). Clin Microbiol Rev 1995; 8 (4): 451-61

91. Dowell SF, Peeling RW, Boman J, et al. Standardizing Chlamydia pneumoniae assays: recommendations from the Centers for Disease Control and Prevention (USA) and the Laboratory Centre for Disease Control (Canada). Clin Infect Dis 2001; 33 (4): 492-503

92. Gencay M, Roth M. Chlamydia pneumoniae infections in asthma: clinical implications. Am J Respir Med 2003; 2 (1): 31-8

93. Khanna M, Fan J, Pehler-Harrington K, et al. The pneumoplex assays, a multiplex PCR-enzyme hybridization assay that allows simultaneous detection of five organisms, Mycoplasma pneumoniae, Chlamydia (Chlamydophila) pneumoniae, Legionella pneumophila, Legionella micdadei, and Bordetella pertussis, and its real-time counterpart. J Clin Microbiol 2005; 43 (2): 565-71

94. Panitch HB. Viral respiratory infections in children with technology dependence and neuromuscular disorders. Pediatr Infect Dis J 2004; 23 (11 Suppl.): S222-7

95. McKimm-Breschkin JL. Management of influenza virus infections with neuraminidase inhibitors: detection, incidence, and implications of drug resistance. Treat Respir Med 2005; 4 (2): 107-16

96. Nichol KL, Mendelman PM, Mallon KP, et al. Effectiveness of live, attenuated intranasal influenza virus vaccine in healthy, working adults: a randomized controlled trial. JAMA 1999; 282 (2): 137-44

97. Belshe RB, Gruber WC, Mendelman PM, et al. Correlates of immune protection induced by live, attenuated, cold-adapted, trivalent, intranasal influenza virus vaccine. J Infect Dis 2000; 181 (3): 1133-7

98. Belshe RB, Gruber WC. Prevention of otitis media in children with live attenuated influenza vaccine given intranasally. Pediatr Infect Dis J 2000; 19 (5 Suppl.): S66-71

99. Halloran ME, Longini Jr IM, Gaglani MJ, et al. Estimating efficacy of trivalent, cold-adapted, influenza virus vaccine (CAIV-T) against influenza A (H1N1) and B using surveillance cultures. Am J Epidemiol 2003; 158 (4): 305-11

100. Feltes TF, Cabalka AK, Meissner HC, et al. Palivizumab prophylaxis reduces hospitalization due to respiratory syncytial virus in young children with hemodynamically significant congenital heart disease. J Pediatr 2003; 143 (4): $532-40$

101. Boeckh M, Berrey MM, Bowden RA, et al. Phase 1 evaluation of the respiratory syncytial virus-specific monoclonal antibody palivizumab in recipients of hematopoietic stem cell transplants. J Infect Dis 2001; 184 (3): 350-4

102. Hicks KL, Chemaly RF, Kontoyiannis DP. Common community respiratory viruses in patients with cancer: more than just 'common colds'. Cancer 2003; 97 (10): 2576-87

103. Guerguerian AM, Gauthier M, Lebel MH, et al. Ribavirin in ventilated respiratory syncytial virus bronchiolitis: a randomized, placebo-controlled trial. Am J Respir Crit Care Med 1999; 160 (3): 829-34

104. Edell D, Khoshoo V, Ross G, et al. Early ribavarin treatment of bronchiolitis: effect on long-term respiratory morbidity. Chest 2002; 122 (3): 935-9

105. Maggon K, Barik S. New drugs and treatment for respiratory syncytial virus. Rev Med Virol 2004; 14 (3): 149-68

106. Hayden FG, Turner RB, Gwaltney JM, et al. Phase II, randomized, double-blind, placebo-controlled studies of ruprintrivir nasal spray 2-percent suspension for prevention and treatment of experimentally induced rhinovirus colds in healthy volunteers. Antimicrob Agents Chemother 2003; 47 (12): 3907-16

107. Dragovich PS, Prins TJ, Zhou R, et al. Structure-based design, synthesis, and biological evaluation of irreversible human rhinovirus $3 \mathrm{C}$ protease inhibitors. 3 . Structure-activity studies of ketomethylene-containing peptidomimetics. J Med Chem 1999; 42 (7): 1203-12 
108. Hsyu PH, Pithavala YK, Gersten M, et al. Pharmacokinetics and safety of an antirhinoviral agent, ruprintrivir, in healthy volunteers. Antimicrob Agents Chemother 2002; 46 (2): 392-7

109. Rotbart HA. Antiviral therapy for enteroviruses and rhinoviruses. Antivir Chem Chemother 2000; 11 (4): 261-71

110. Anzueto A, Niederman MS. Diagnosis and treatment of rhinovirus respiratory infections. Chest 2003; 123 (5): 1664-72

111. King VJ, Viswanathan M, Bordley WC, et al. Pharmacologic treatment of bronchiolitis in infants and children: a systematic review. Arch Pediatr Adolesc Med 2004; 158 (2): 127-37

112. Scarfone RJ. Controversies in the treatment of bronchiolitis. Curr Opin Pediatr 2005; 17 (1): 62-6

113. Esposito S, Bosis S, Faelli N, et al. Role of atypical bacteria and azithromycin therapy for children with recurrent respiratory tract infections. Pediatr Infect Dis J 2005; 24 (5): 438-44

114. Schmidt SM, Muller CE, Gurtler L, et al. Chlamydophila pneumoniae respiratory tract infection aggravates therapy refractory bronchitis or pneumonia in childhood. Klin Padiatr 2005; 217 (1): 9-14

115. Korppi M. Community-acquired pneumonia in children: issues in optimizing antibacterial treatment. Paediatr Drugs 2003; 5 (12): 821-32

116. Hammerschlag MR. Pneumonia due to Chlamydia pneumoniae in children: epidemiology, diagnosis, and treatment. Pediatr Pulmonol 2003; 36 (5): 384-90

117. Buckingham SC. Tick-borne infections in children: epidemiology, clinical manifestations, and optimal management strategies. Paediatr Drugs 2005; 7 (3): 163-76

118. Cunha BA. Doxycycline for community-acquired pneumonia. Clin Infect Dis 2003; 37 (6): 870

119. Singh M, Salaria M, Kumar L. Pneumonic presentation of brucellosis. Indian J Pediatr 2005; 72 (1): 65-6

120. White NJ. Melioidosis. Lancet 2003; 361 (9370): 1715-22

121. Cuzzolin L, Fanos V. Safety of fluoroquinolones in paediatrics. Expert Opin Drug Saf 2002; 1 (4): 319-24

122. Gendrel D, Chalumeau M, Moulin F, et al. Fluoroquinolones in paediatrics: a risk for the patient or for the community? Lancet Infect Dis 2003; 3 (9): 537-46

123. Block S, Hedrick J, Hammerschlag MR, et al. Mycoplasma pneumoniae and Chlamydia pneumoniae in pediatric community-acquired pneumonia: comparative efficacy and safety of clarithromycin vs erythromycin ethylsuccinate. Pediatr Infect Dis J 1995; 14 (6): 471-7

124. Kastner U, Guggenbichler JP. Influence of macrolide antibiotics on promotion of resistance in the oral flora of children. Infection 2001; 29 (5): 251-6
125. Morita JY, Kahn E, Thompson T, et al. Impact of azithromycin on oropharyngeal carriage of group A Streptococcus and nasopharyngeal carriage of macrolideresistant Streptococcus pneumoniae. Pediatr Infect Dis J 2000; 19 (1): 41-6

126. Zuckerman JM. The newer macrolides: azithromycin and clarithromycin. Infect Dis Clin North Am 2000; 14 (2): 449-62

127. Harris JA, Kolokathis A, Campbell M, et al. Safety and efficacy of azithromycin in the treatment of community-acquired pneumonia in children. Pediatr Infect Dis J 1998; 17 (10): 865-71

128. Wubbel L, Muniz L, Ahmed A, et al. Etiology and treatment of communityacquired pneumonia in ambulatory children. Pediatr Infect Dis J 1999; 18 (2): 98-104

129. Ruuskanen O. Safety and tolerability of azithromycin in pediatric infectious diseases: 2003 update. Pediatr Infect Dis J 2004; 23 (2 Suppl.): S135-9

130. Prescott Jr WA, Johnson CE. Antiinflammatory therapies for cystic fibrosis: past, present, and future. Pharmacotherapy 2005; 25 (4): 555-73

131. Saiman L. The use of macrolide antibiotics in patients with cystic fibrosis. Curr Opin Pulm Med 2004; 10 (6): 515-23

132. Amsden GW. Anti-inflammatory effects of macrolides: an underappreciated benefit in the treatment of community-acquired respiratory tract infections and chronic inflammatory pulmonary conditions? J Antimicrob Chemother 2005; 55 (1): 10-21

133. Yates B, Murphy DM, Forrest IA, et al. Azithromycin reverses airflow obstruction in established bronchiolitis obliterans syndrome. Am J Respir Crit Care Med 2005; 172 (6): 772-5

134. Strachan D, Burton I, Pearson GJ. Is oral azithromycin effective for the treatment of cyclosporine-induced gingival hyperplasia in cardiac transplant recipients? J Clin Pharm Ther 2003; 28 (4): 329-38

135. Principi N, Esposito S. Mycoplasma pneumoniae and Chlamydia pneumoniae cause lower respiratory tract disease in paediatric patients. Curr Opin Infect Dis 2002; 15 (3): 295-300

Correspondence and offprints: Dr Oliver Schildgen, Department of Virology, Institute for Medical Microbiology, Immunology, and Parasitology, University of Bonn, Sigmund-Freud-Strasse 25, Bonn, 53105, Germany. E-mail: schildgen@mibi03.meb.uni-bonn.de 